\title{
MSMB gene rs10993994 polymorphism increases the risk of prostate cancer
}

\author{
Tao Peng ${ }^{1}$, Lifeng Zhang ${ }^{2}$, Lijie Zhu ${ }^{1}$, Yuan-Yuan Mi ${ }^{1}$ \\ ${ }^{1}$ Department of Urology, The Third Affiliated Hospital of Nantong University, Wuxi, PR China \\ ${ }^{2}$ Department of Urology, Changzhou No.2 People's Hospital Affiliated to Nanjing Medical University, Changzhou, Jiangsu \\ Province, China \\ Correspondence to: Lifeng Zhang, email: 3258479087@qq.com \\ Lijie Zhu, email: lijie_zhumed@163.com \\ Yuan-Yuan Mi, email: myywxsy2016@sina.com
}

Keywords: MSMB, prostate cancer, rs 10993994, meta-analysis, single nucleotide polymorphism

Received: December 01,2016 Accepted: January 11,2017 Published: February 14, 2017

Copyright: Peng et al. This is an open-access article distributed under the terms of the Creative Commons Attribution License (CC-BY), which permits unrestricted use, distribution, and reproduction in any medium, provided the original author and source are credited.

\section{ABSTRACT}

\begin{abstract}
Genome-wide association studies (GWASs) identified microseminoprotein- $\beta$ (MSMB) gene rs10993994 polymorphism was significantly associated with prostate cancer (PC) risk. However, the association between MSMB gene rs10993994 polymorphism and PC risk remains controversial. Therefore, we performed a systematic review and meta-analysis by searching in the databases of PubMed, and Embase. Pooled odds ratios (ORs) and 95\% confidence intervals (CIs) were calculated by using fixed-effect or random-effect models. A total of 11 publications containing 13 case-control studies for rs10993994 polymorphism were included in our analysis. Our data indicated that MSMB gene rs10993994 polymorphism was associated with an increased risk of PC. Stratification analyses of ethnicity suggested rs10993994 polymorphism increased the risk of PC among Caucasians, but not among Asians. In conclusion, this meta-analysis indicates that MSMB gene rs10993994 polymorphism increases the risk of PC.
\end{abstract}

\section{INTRODUCTION}

Prostate cancer (PC) is the second most common cancer among men worldwide [1]. Several risk factors including age, family history and ethnic origin have been identified [2]. The etiology of PC remains largely unknown. Data suggested that $30-40 \%$ of all earlyonset PC $(<55$ years) are caused by inherited factors [3], indicating the genetic factor of this disease. Hereditary susceptibility is recognized as the strongest risk factor for PC [4].

Three most abundant proteins secreted by the prostate include Microseminoprotein- $\beta$ (MSMB), prostatic acid phosphatase (PAP) and prostate-specific antigen (PSA) [5]. This MSMB gene codes for protein of 94 amino acids (PSP94), a predominant protein secreted by the prostate tissue and an important candidate gene for PC. More than 40 PC susceptibility loci have been identified [6], which could explain about $25 \%$ of the familial risk in this disorder. Among these single nucleotide polymorphisms (SNPs), several genome-wide association studies (GWASs) identified rs10993994 polymorphism in the promoter region of MSMB gene [7, 8], which was significantly associated with PC susceptibility. Subsequent studies [9-18] also investigated the association between MSMB gene rs10993994 polymorphism and PC susceptibility, but with conflicting conclusions. These studies were conflicting and inconclusive probably due to different ethnic populations, clinical heterogeneity, and small sample sizes. Therefore, we conducted a comprehensive meta-analysis to explore the possible association between MSMB gene rs10993994 polymorphism and PC risk. 


\section{RESULTS}

\section{Characteristics of the included studies}

We yielded 58 citations after database searching. 35 citations were removed after removing duplicates and screening the titles and abstracts. 22 citations were selected for further full text review. 11 citations were excluded: 7 did not provide detailed genotyping data; 2 not case-control studies; 1 was about other diseases; 1 investigated other polymorphisms. We finally identified 11 eligible citations [8-18] including 13 studies $(31,584$ cases and 30,251 controls) in this meta-analysis. Selection for eligible studies included in this meta-analysis was presented in Figure 1. The characteristics of included studies are summarized in Table 1. The Newcastle-Ottawa Scale (NOS) scores of all included studies ranged from 5 to 7 stars, suggesting that these studies were of high methodological quality. All included studies conformed to Hardy-Weinberg equilibrium (HWE).

\section{Quantitative synthesis}

As shown in Table 2, we detected a significant association between MSMB gene rs10993994 polymorphism with an increased PC risk $(\mathrm{CT}+\mathrm{TT}$ vs.
CC: OR, 1.27; 95\% CI, 1.14-1.41, $P<0.001$, Figure 2). Stratification analyses were conducted according to ethnicity and source of controls (SOCs). Our data indicated that rs 10993994 polymorphism was significantly associated with an increased risk of PC among Caucasian populations, but not among Asian populations (Table 3). As for other populations, a weak association was detected among African-Americans and mixed populations. Regarding stratification analysis by source of controls (SOCs), similar result was obtained in both populationbased controls and hospital-based controls (TT vs. $\mathrm{CT}+\mathrm{CC}$, Figure 3 ).

We assessed sensitivity by omitting each study once at a time in every genetic model for rs10993994 polymorphism. The pooled ORs for the effects about this polymorphism indicated that our data were stable and trustworthy (TT vs. CT $+\mathrm{CC}$, Figure 4). Both Egger's and Begg's tests (CT+TT vs. CC, Figure 5) were used to evaluate the publication bias of this meta-analysis. Our data revealed that there was no obvious publication bias for rs10993994 polymorphism. Due to significant between-study heterogeneity among every genetic model, we conductedmeta-regression to explore whether ethnicity and source of controlswere the resource of heterogeneity. However, our data suggested that ethnicity and source

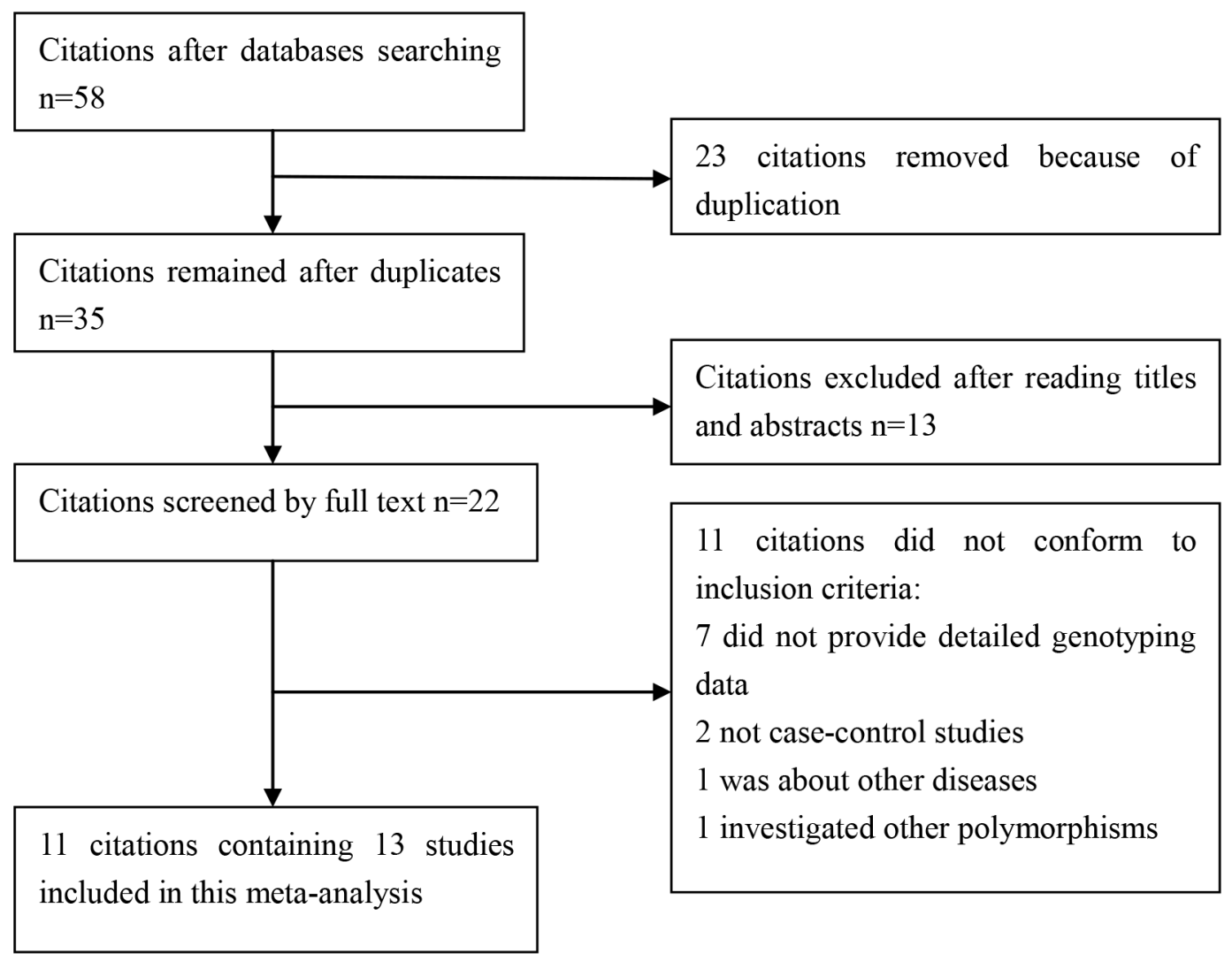

Figure 1: Selection for eligible citations included in this meta-analysis. 
Table 1: Characteristics of included studies

\begin{tabular}{|c|c|c|c|c|c|c|c|c|c|c|c|}
\hline Author and year & SOC & $\begin{array}{l}\text { Genotype } \\
\text { methods }\end{array}$ & Ethnicity & Case & & & Control & & & HWE & NOS \\
\hline & & & & $\mathrm{CC}$ & CT & TT & $\mathrm{CC}$ & CT & TT & & \\
\hline Sjoblom 2016 & HB & PCR & Caucasian & 154 & 160 & 54 & 394 & 396 & 111 & $\mathrm{Y}$ & 6 \\
\hline Mhatre2015 & PB & PCR & Asian & 9 & 24 & 17 & 5 & 10 & 15 & $\mathrm{Y}$ & 7 \\
\hline Shui2014 & $\mathrm{PB}$ & TaqMan & Caucasian & 3289 & 5168 & 2030 & 4102 & 5245 & 1677 & $\mathrm{Y}$ & 6 \\
\hline Stott-Miller2013 & PB & Taqman & Caucasian & 377 & 621 & 241 & 465 & 599 & 168 & $\mathrm{Y}$ & 7 \\
\hline FitzGerald2013 & PB & Taqman & Caucasian & 382 & 633 & 242 & 472 & 608 & 173 & $\mathrm{Y}$ & 7 \\
\hline Haiman2013 & PB & AutoDELFIA & Mixed & 314 & 588 & 319 & 359 & 585 & 286 & $\mathrm{Y}$ & 6 \\
\hline Но2012 & $\mathrm{PB}$ & PCR & Caucasian & 83 & 94 & 65 & 102 & 119 & 43 & $\mathrm{Y}$ & 6 \\
\hline Chang2011 & HB & PCR & African-American & 1553 & 1904 & 583 & 1349 & 1799 & 600 & $\mathrm{Y}$ & 7 \\
\hline Xu2010 & PB & Taqman & Asian & 57 & 122 & 72 & 71 & 140 & 47 & $\mathrm{Y}$ & 6 \\
\hline Chang2009a & PB & PCR & Caucasian & 963 & 1354 & 546 & 627 & 810 & 264 & $\mathrm{Y}$ & 6 \\
\hline Chang2009b & HB & PCR & Caucasian & 1380 & 2129 & 935 & 1275 & 1584 & 491 & $\mathrm{Y}$ & 6 \\
\hline Eeles2008a & HB & HapMap & Caucasian & 543 & 921 & 390 & 815 & 854 & 225 & $\mathrm{Y}$ & 6 \\
\hline Eeles2008b & HB & НарМар & Caucasian & 960 & 1622 & 686 & 1204 & 1618 & 544 & $\mathrm{Y}$ & 6 \\
\hline
\end{tabular}

SOC, source of controls; PB, population-based controls; HB, hospital-based controls; HWE, Hardy-Weinberg equilibrium; NOS, Newcastle-Ottawa Scale.

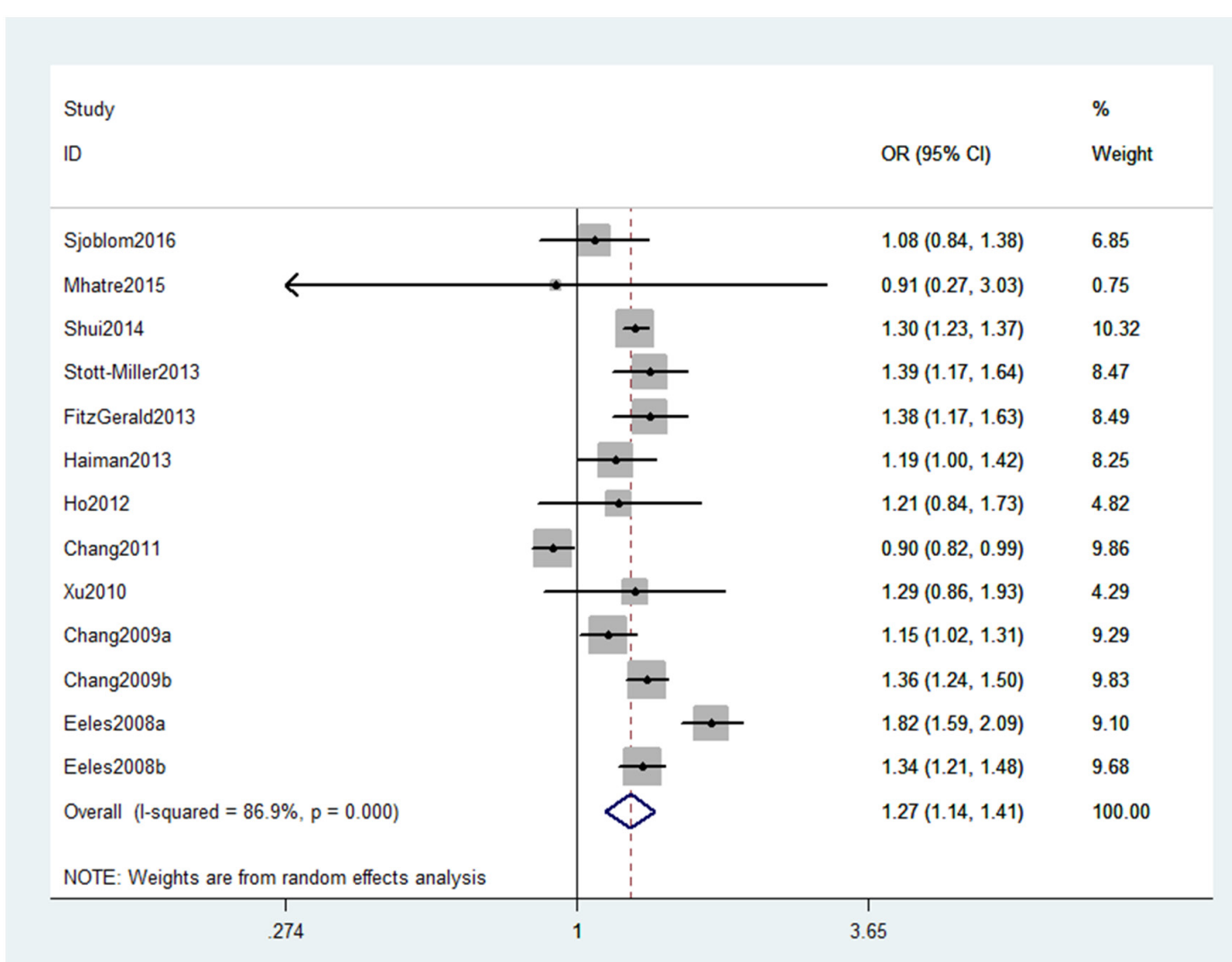

Figure 2: Forest plot shows odds ratio for the associations between rs10993994 polymorphism and PC risk (CT+TT vs. CC). 
Table 2: Meta-analysis of association between MSMB rs10993994 polymorphism and prostate cancer risk

\begin{tabular}{lccccc}
\hline Comparison & OR(95\%CI) & $\boldsymbol{P}$-value & $\begin{array}{c}\boldsymbol{P} \text { for } \\
\text { heterogeneity }\end{array}$ & $\mathbf{I}^{\mathbf{2}(\%)}$ & Model \\
\hline T vs. C & $1.23(1.13,1.34)$ & $<0.001$ & $<0.001$ & 90.6 & Random \\
CT+TT vs. CC & $1.27(1.14,1.41)$ & $<0.001$ & $<0.001$ & 86.9 & Random \\
TT vs. CT+CC & $1.37(1.21,1.56)$ & $<0.001$ & $<0.001$ & 85.2 & Random \\
\hline
\end{tabular}

of controls did not seem to be responsible for the heterogeneity (data not shown).

\section{DISCUSSION}

This is the first meta-analysis to investigate the association between MSMB gene rs10993994 polymorphism and PC susceptibility. Our data indicated that MSMB gene rs10993994 polymorphism increased the risk of PC. Stratification analyses of ethnicity suggested that rs10993994 polymorphism was associated with an increased risk of PC only among Caucasians.

The MSMB gene is located on chromosome 10q11.2 [19]. MSMB codes for a secreted seminoprotein. This protein has tumour suppressor properties and is silent in prostate tumour tissues [20]. Over expression of MSMB could induce PC cell apoptosis and suppress prostate cancer growth, invasion and metastasis $[11,21]$. Harries et al. indicated that alterations in MSMB gene expression are associated with the development of PC [4]. The SNP rs10993994 is located in the promoter region of MSMB

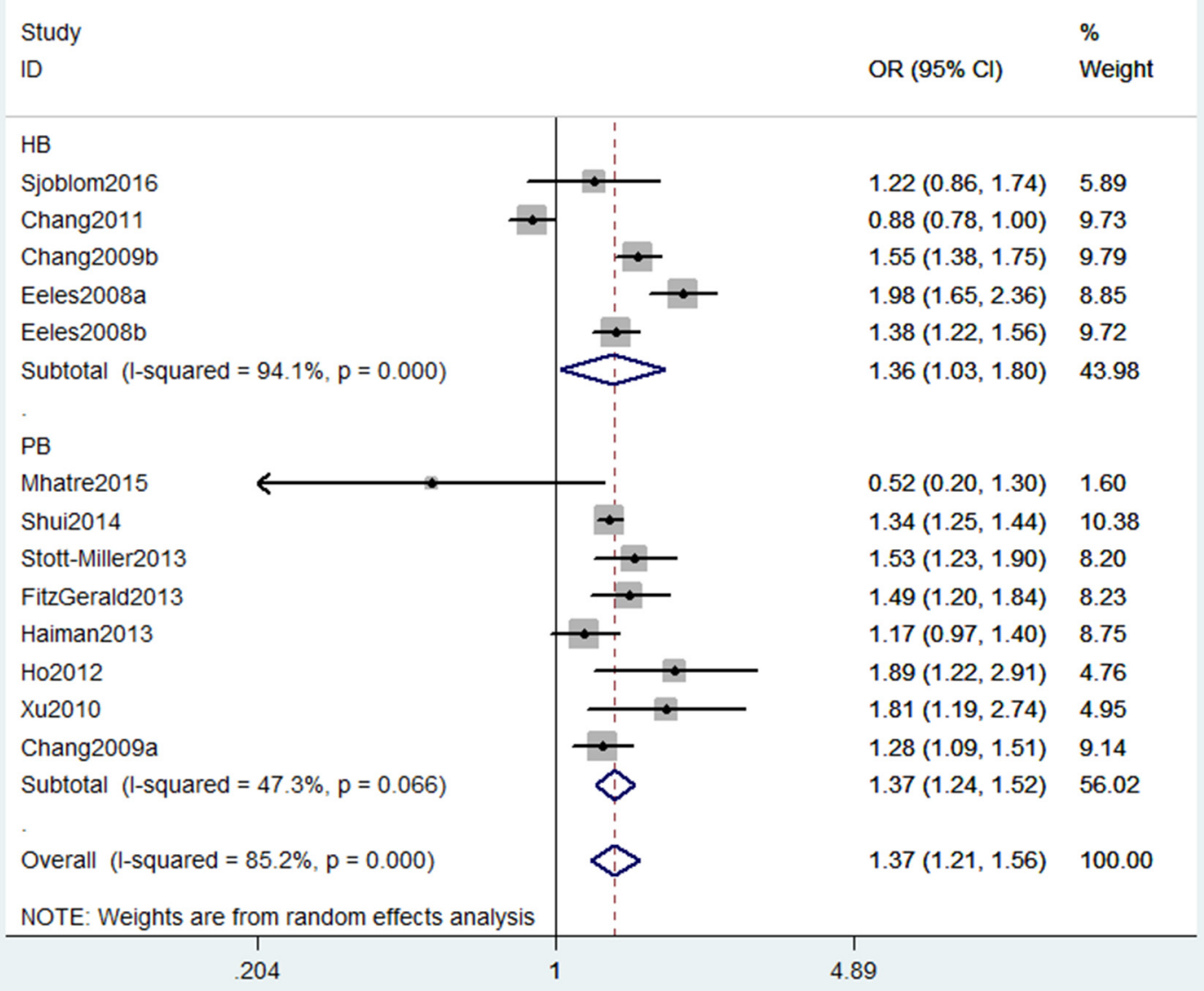

Figure 3: Stratification analyses by source of controls between rs10993994 polymorphism and PC risk (TT vs. CT+CC). 
Table 3: Summary of the subgroup analyses in this meta-analysis

\begin{tabular}{|c|c|c|c|c|c|}
\hline Comparison & Category & Category & Studies & OR $(95 \%$ CI $)$ & $P$-value \\
\hline \multirow[t]{6}{*}{ T vs. C } & Ethnicity & Caucasian & 9 & $1.29(1.21,1.37)$ & $<0.001$ \\
\hline & & Asian & 2 & $1.04(0.55,1.99)$ & 0.899 \\
\hline & & $\begin{array}{l}\text { African- } \\
\text { American }\end{array}$ & 1 & $1.14(1.02,1.27)$ & 0.026 \\
\hline & & Mixed & 1 & $0.92(0.86,0.98)$ & 0.010 \\
\hline & SOC & HB & 5 & $1.22(1.01,1.48)$ & 0.043 \\
\hline & & PB & 8 & $1.23(1.17,1.29)$ & $<0.001$ \\
\hline \multirow[t]{6}{*}{$\mathrm{CT}+\mathrm{TT}$ vs. CC } & Ethnicity & Caucasian & 9 & $1.34(1.24,1.46)$ & $<0.001$ \\
\hline & & Asian & 2 & $1.25(0.85,1.83)$ & 0.256 \\
\hline & & $\begin{array}{l}\text { African- } \\
\text { American }\end{array}$ & 1 & $1.19(1.00,1.42)$ & 0.054 \\
\hline & & Mixed & 1 & $0.90(0.82,0.99)$ & 0.026 \\
\hline & $\mathrm{SOC}$ & HB & 5 & $1.27(1.00,1.61)$ & 0.054 \\
\hline & & PB & 8 & $1.28(1.22,1.34)$ & $<0.001$ \\
\hline \multirow[t]{6}{*}{ TT vs. CT $+\mathrm{CC}$} & Ethnicity & Caucasian & 9 & $1.48(1.34,1.62)$ & $<0.001$ \\
\hline & & Asian & 2 & $1.03(0.31,3.51)$ & 0.956 \\
\hline & & $\begin{array}{l}\text { African- } \\
\text { American }\end{array}$ & 1 & $1.17(0.97,1.40)$ & 0.099 \\
\hline & & Mixed & 1 & $0.88(0.78,1.00)$ & 0.053 \\
\hline & SOC & HB & 5 & $1.36(1.03,1.80)$ & 0.032 \\
\hline & & PB & 8 & $1.37(1.24,1.52)$ & $<0.001$ \\
\hline
\end{tabular}

SOC, source of controls; PB, population-based controls; HB, hospital-based controls.

gene. Studies [22, 23] have demonstrated that the risk allele of rs10993994 polymorphism was significantly associated with decreased expression of MSMB mRNA and protein in prostate tissues. It is reasonable to hypothesize that MSMB gene rs10993994 polymorphism plays a pivotal role in the pathogenesis of PC.

To date, many studies [8-18] explored the association between MSMB gene 10993994 polymorphism and $\mathrm{PC}$ risk. However, these studies detected conflicting results. To achieve reliable conclusions, we conducted a meta-analysis to demonstrate the associations between this SNP and PC susceptibility. Our data indicated that MSMB rs10993994 polymorphism increased the risk of PC. Stratification analyses of ethnicity in this study suggested that this SNP was associated with an increased risk of PC among Caucasians, while no association was detected among Asians. As for other populations, we found a weak association among African-Americans and mixed populations. Obviously, diversity inheritance of different ethnicities was presented in this meta-analysis. The reasons why their conclusions in diverse ethnicities vary are still unclear. It may be partially explained by different ethnic groups with various genetic backgrounds, small sample sizes, and clinical heterogeneity. It is noteworthy that the sample sizes of Asians and African-Americans are limited. Therefore, larger studies are needed to identify the possible association in those ethnicities. Additionally, we conducted stratified analysis by source of controls and similar positive results were obtained in both populationbased studies and hospital-based studies.

To seek the sources of high heterogeneity in this study, we conducted meta-regression analysis, stratification analyses, and sensitivity analysis. Metaregression analysis of ethnicity and source of controls was conducted. Our data confirmed that ethnicity and source of controls were not the sources of heterogeneity. Stratification analysis and sensitivity analysis also did not find the sources of heterogeneity. Clinical heterogeneity and different environments might be the reasons for high heterogeneity, which needs further studies to validate.

We believe this meta-analysis has some strength. First, we identified 13 studies with large sample sizes including 31,584 cases and 30,251 controls. Second, sensitivity analysis indicated that our data regarding rs10993994 polymorphism were stable and dependable (Figure 4). Third, this study had a power of $99.9 \%$ to 


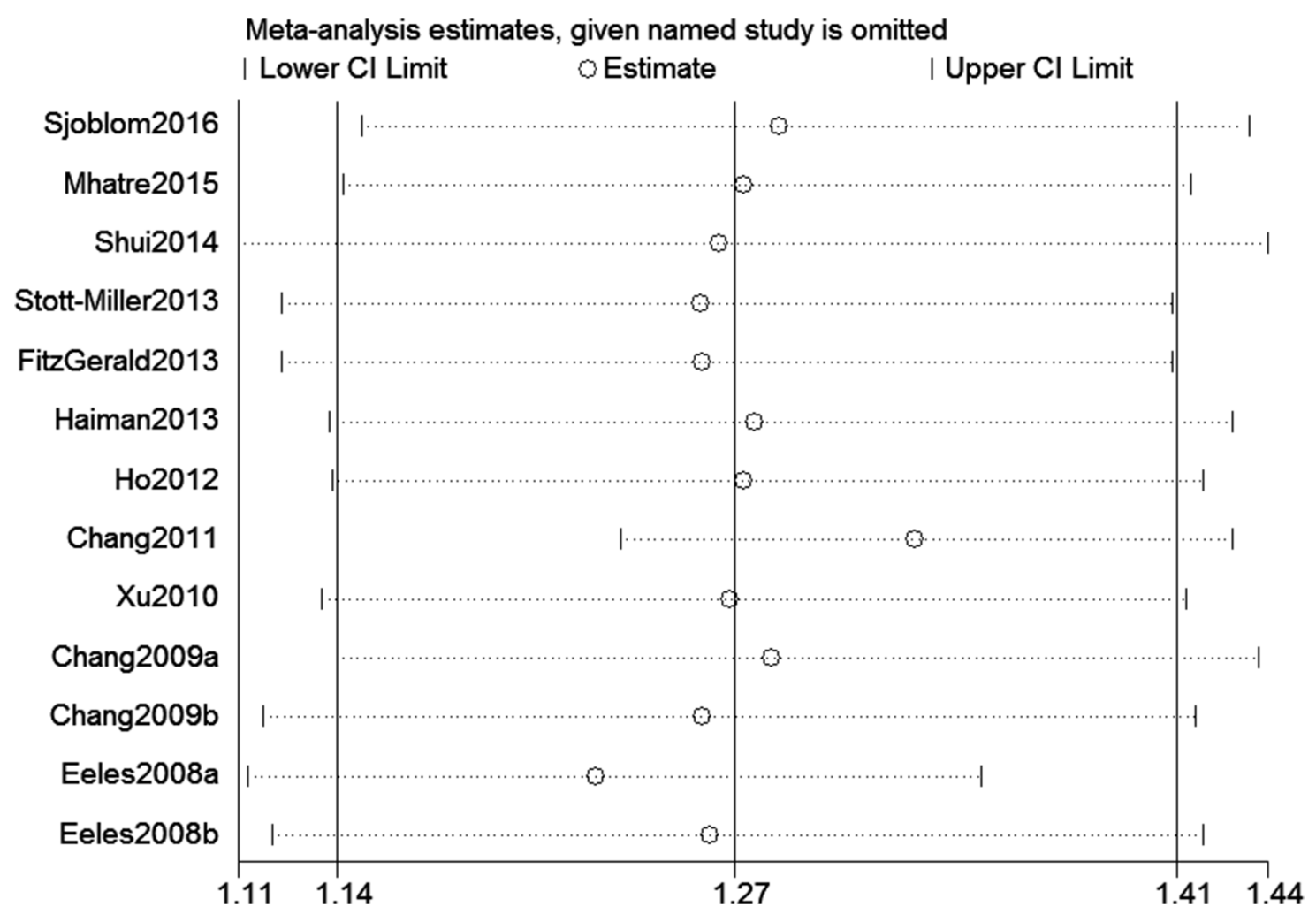

Figure 4: Sensitivity analysis about rs10993994 polymorphism and PC risk (TT vs. CT+CC).

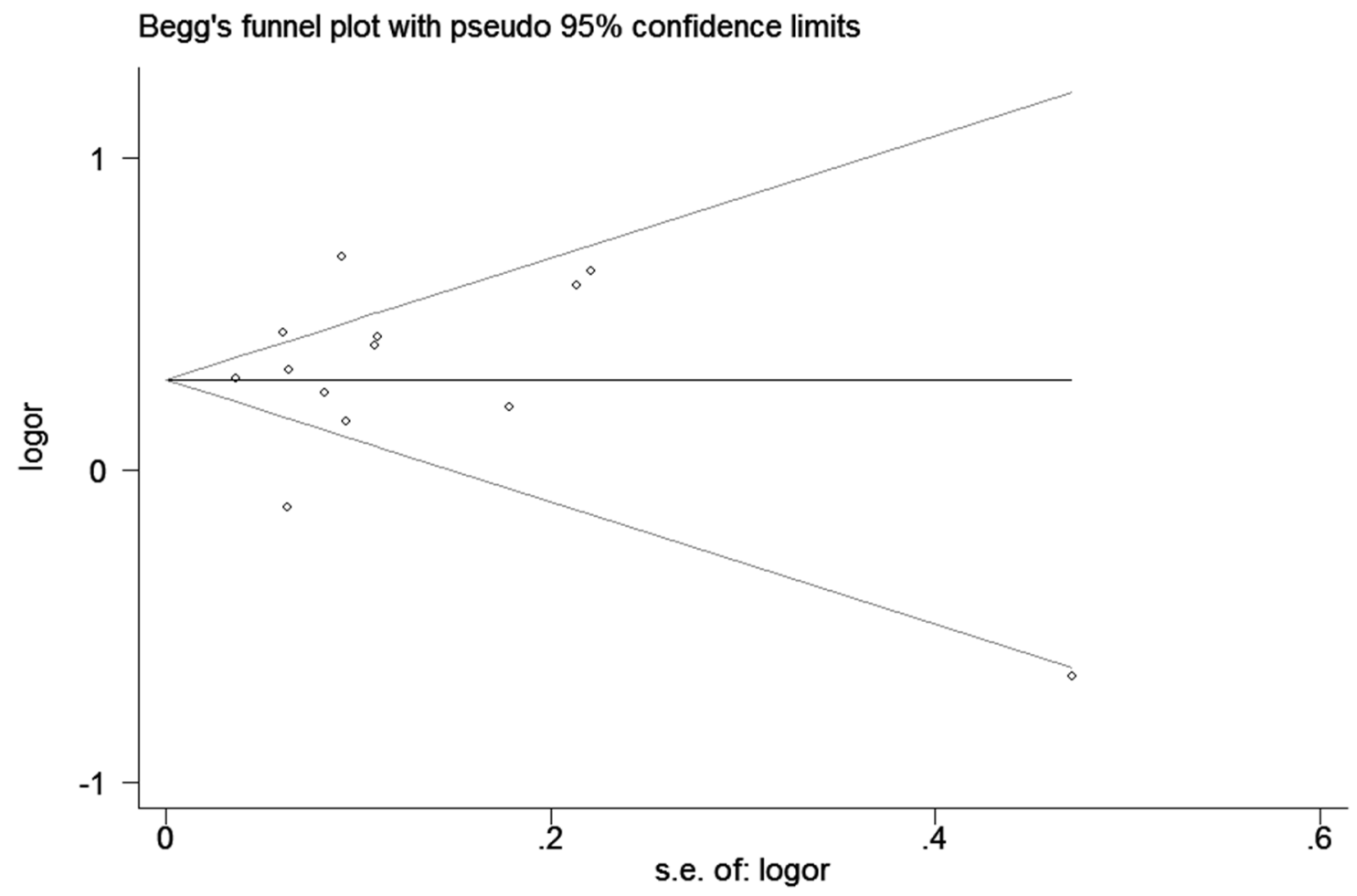

Figure 5: Begg's tests about rs10993994 polymorphism and PC risk (CT+TT vs. CC). 
detect the effect of rs10993994 polymorphism on PC susceptibility, assuming an OR of 1.27.

However, potential limitations should be addressed in this meta-analysis. First, due to limited data, we could not perform further stratification analyses of other potential factors, such as age. Second, our results were based on unadjusted estimates for confounding factors, which might influence the final findings. Third, we could not assess potential gene-gene and gene-environment interactions. Fourth, the sample sizes of stratification analyses were limited in some ethnicities, such as Asians and African-Americans.

In summary, this meta-analysis indicates that MSMB gene rs 10993994 polymorphism increased the risk of PC, especially among Caucasians. Further studies are necessary to validate whether this SNP is associated with RA susceptibility in other ethnic groups.

\section{MATERIALS AND METHODS}

\section{Literature search and criteria of inclusion}

We systematically searched the PubMed, and Embase to identify studies through June 15, 2016. The following search terms were used: "prostate cancer," "PC," "MSMB," "Microseminoprotein- $\beta$," "SNP" and "polymorphism". No restrictions were placed on the literature search. Additional initially omitted studies were identified by hand screening. The inclusion criteria of studies were as following: (1) studies that evaluated the association between MSMB gene rs10993994 polymorphism and PC risk, (2) studied on human beings, (3) study provided sufficient data to calculate the odds ratios (ORs) and $95 \%$ confidence intervals (CIs), and $P$ value, and (4) case-control study. Exclusion criteria were: (1) a duplication of previous publications; (2) a review, editorial or other non-original study; (3) studies without detailed genotype data, and (4) inclusion of subjects with other diseases that might influence the results.

\section{Data extraction and quality assessment}

Data was extracted from all eligible studies by two reviewers. The extracted information from all eligible studies including: name of first author, publication year, ethnicity, source of controls, and genotype numbers of cases and controls. Two reviewers independently conducted the extraction of data and assessed the study quality according to the NOS [24]. All disagreements were resolved by discussion.

\section{Statistical analysis}

The crude ORs and $95 \%$ CIs were used to assess the strength of associations between MSMB gene rs 10993994 polymorphism and PC risk. Stratification analysis was carried out by ethnicity and SOC. When a $\mathrm{Q}$ test indicated $P<0.1$ or $\mathrm{I}^{2}>50 \%$ indicated heterogeneity across studies, a random-effect model was used. Otherwise, the fixed-effects model was applied [25]. Pooled ORs were calculated for allele model, dominant model, and recessive model. We performed leave-one-out sensitivity analysis to evaluate the stability of the overall results. We assessed the departure from the HWE in the controls using Pearson's $\chi 2$ test. Begger's and Egger's linear regression test were used to detect the potential publication bias [26]. The power of this meta-analysis was calculated at a significant value of 0.05 [27]. Meta-regression analysis of ethnicity and SOC was performed to seek the main sources of the heterogeneity. All statistical analyses were performed using the Stata 11.0 software (STATA Corporation, College Station, TX, USA).

\section{Abbreviations}

PC, prostate cancer; MSMB, microseminoprotein- $\beta$; PAP, prostatic acid phosphatase; PSA, prostate-specific antigen; CI, confidence interval; OR, odds ratio; NOS, Newcastle-Ottawa Scale; HWE, Hardy-Weinberg equilibrium; SNP, single nucleotide polymorphism; GWAS, genome-wide association study.

\section{CONFLICTS OF INTEREST}

The authors declare no conflicts of interest.

\section{REFERENCES}

1. Ferlay J, Soerjomataram I, Dikshit R, Eser S, Mathers C, Rebelo M, Parkin DM, Forman D, Bray F. Cancer incidence and mortality worldwide: sources, methods and major patterns in GLOBOCAN 2012. International journal of cancer. 2015; 136:E359-386.

2. Johns LE, Houlston RS. A systematic review and metaanalysis of familial prostate cancer risk. BJU international. 2003; 91:789-794.

3. Bratt O. Hereditary prostate cancer: clinical aspects. The Journal of urology. 2002; 168:906-913.

4. Harries LW, Perry JR, McCullagh P, Crundwell M. Alterations in LMTK2, MSMB and HNF1B gene expression are associated with the development of prostate cancer. BMC cancer. 2010; 10:315.

5. Abrahamsson PA, Lilja H, Falkmer S, Wadstrom LB. Immunohistochemical distribution of the three predominant secretory proteins in the parenchyma of hyperplastic and neoplastic prostate glands. The Prostate. 1988; 12:39-46.

6. Kote-Jarai Z, Olama AA, Giles GG, Severi G, Schleutker J, Weischer M, Campa D, Riboli E, Key T, Gronberg H, Hunter DJ, Kraft P, Thun MJ, et al. Seven prostate cancer susceptibility loci identified by a multi-stage genome-wide association study. Nature genetics. 2011; 43:785-791. 
7. Thomas G, Jacobs KB, Yeager M, Kraft P, Wacholder S, Orr N, Yu K, Chatterjee N, Welch R, Hutchinson A, Crenshaw A, Cancel-Tassin G, Staats BJ, et al. Multiple loci identified in a genome-wide association study of prostate cancer. Nature genetics. 2008; 40:310-315.

8. Eeles RA, Kote-Jarai Z, Giles GG, Olama AA, Guy M, Jugurnauth SK, Mulholland S, Leongamornlert DA, Edwards SM, Morrison J, Field HI, Southey MC, Severi G, et al. Multiple newly identified loci associated with prostate cancer susceptibility. Nature genetics. 2008; 40:316-321.

9. Ho CK, Halley L, Wei J, Habib FK. Analysis of prostate cancer association with four single-nucleotide polymorphisms from genome-wide studies and serum phyto-estrogen concentrations. Prostate cancer and prostatic diseases. 2012; 15:365-368.

10. Chang BL, Cramer SD, Wiklund F, Isaacs SD, Stevens VL, Sun J, Smith S, Pruett K, Romero LM, Wiley KE, Kim ST, Zhu Y, Zhang Z, et al. Fine mapping association study and functional analysis implicate a SNP in MSMB at 10q11 as a causal variant for prostate cancer risk. Human molecular genetics. 2009; 18:1368-1375.

11. Xu B, Wang J, Tong N, Mi Y, Min Z, Tao J, Li P, Cheng G, Li J, Wang M, Tang J, Song N, Zhang Z, et al. A functional polymorphism in MSMB gene promoter is associated with prostate cancer risk and serum MSMB expression. The Prostate. 2010; 70:1146-1152.

12. FitzGerald LM, Zhang X, Kolb S, Kwon EM, Liew YC, Hurtado-Coll A, Knudsen BS, Ostrander EA, Stanford JL. Investigation of the relationship between prostate cancer and MSMB and NCOA4 genetic variants and protein expression. Human mutation. 2013; 34:149-156.

13. Haiman CA, Stram DO, Vickers AJ, Wilkens LR, Braun K, Valtonen-Andre C, Peltola M, Pettersson K, Waters KM, Marchand LL, Kolonel LN, Henderson BE, Lilja H. Levels of beta-microseminoprotein in blood and risk of prostate cancer in multiple populations. Journal of the National Cancer Institute. 2013; 105:237-243.

14. Sjoblom L, Saramaki O, Annala M, Leinonen K, Nattinen J, Tolonen T, Wahlfors T, Nykter M, Bova GS, Schleutker J, Tammela TL, Lilja H, Visakorpi T. MicroseminoproteinBeta Expression in Different Stages of Prostate Cancer. PloS one. 2016; 11:e0150241.

15. Stott-Miller M, Wright JL, Stanford JL. MSMB gene variant alters the association between prostate cancer and number of sexual partners. The Prostate. 2013; 73:1803-1809.

16. Shui IM, Lindstrom S, Kibel AS, Berndt SI, Campa D, Gerke T, Penney KL, Albanes D, Berg C, Bueno-deMesquita HB, Chanock S, Crawford ED, Diver WR, et al. Prostate cancer $(\mathrm{PCa})$ risk variants and risk of fatal $\mathrm{PCa}$ in the National Cancer Institute Breast and Prostate Cancer Cohort Consortium. European urology. 2014; 65:1069-1075.
17. Mhatre DR, Mahale SD, Khatkhatay MI, Achrekar SK, Desai SS, Jagtap DD, Dhabalia JV, Tongaonkar HB, Dandekar SP, Varadkar AM. The rs10993994 in the proximal MSMB promoter region is a functional polymorphism in Asian Indian subjects. SpringerPlus. 2015; $4: 380$.

18. Chang BL, Spangler E, Gallagher S, Haiman CA, Henderson B, Isaacs W, Benford ML, Kidd LR, Cooney K, Strom S, Ingles SA, Stern MC, Corral R, et al. Validation of genome-wide prostate cancer associations in men of African descent. Cancer epidemiology, biomarkers \& prevention. 2011; 20:23-32.

19. Sasaki T, Matsumoto N, Jinno Y, Niikawa N, Sakai H, Kanetake H, Saito Y. Assignment of the human betamicroseminoprotein gene (MSMB) to chromosome 10q11.2. Cytogenetics and cell genetics. 1996; 72:177-178.

20. Beke L, Nuytten M, Van Eynde A, Beullens M, Bollen M. The gene encoding the prostatic tumor suppressor PSP94 is a target for repression by the Polycomb group protein EZH2. Oncogene. 2007; 26:4590-4595.

21. Shukeir N, Arakelian A, Kadhim S, Garde S, Rabbani SA. Prostate secretory protein PSP-94 decreases tumor growth and hypercalcemia of malignancy in a syngenic in vivo model of prostate cancer. Cancer research. 2003; 63:2072-2078.

22. Pomerantz MM, Shrestha Y, Flavin RJ, Regan MM, Penney KL, Mucci LA, Stampfer MJ, Hunter DJ, Chanock SJ, Schafer EJ, Chan JA, Tabernero J, Baselga J, et al. Analysis of the 10q11 cancer risk locus implicates MSMB and NCOA4 in human prostate tumorigenesis. PLoS genetics. 2010; 6:e1001204.

23. Whitaker HC, Kote-Jarai Z, Ross-Adams H, Warren AY, Burge J, George A, Bancroft E, Jhavar S, Leongamornlert D, Tymrakiewicz M, Saunders E, Page E, Mitra A, et al. The rs10993994 risk allele for prostate cancer results in clinically relevant changes in microseminoprotein-beta expression in tissue and urine. PloS one. 2010; 5:e13363.

24. Stang A. Critical evaluation of the Newcastle-Ottawa scale for the assessment of the quality of nonrandomized studies in meta-analyses. European journal of epidemiology. 2010; 25:603-605.

25. Higgins JP, Thompson SG. Quantifying heterogeneity in a meta-analysis. Statistics in medicine. 2002; 21:1539-1558.

26. Peters JL, Sutton AJ, Jones DR, Abrams KR, Rushton L. Comparison of two methods to detect publication bias in meta-analysis. Jama. 2006; 295:676-680.

27. Hedges LV, Pigott TD. The power of statistical tests in meta-analysis. Psychological methods. 2001; 6:203-217. 